\title{
INFLUENCE OF MESOFORMS OF A RELIEF ON AGROPHYSICAL PROPERTIES OF SOIL OF CHERNOZEM ORDINARY IN THE CONDITIONS OF ORENBURG PREDURALJE
}

\section{ВЛИЯНИЕ МЕЗОФОРМ РЕЛЬЕФА НА АГРОФИЗИЧЕСКИЕ СВОЙСТВА ПОЧВЫ ЧЕРНОЗЕМА ОБЫКНОВЕННОГО В УСЛОВИЯХ ОРЕНБУРГСКОГО ПРЕДУРАЛЬЯ}

\section{A. Solovykh, V. Lukjantsev, S. Dushkin, G. Sudarenkov, Post-graduate students}

А.А. Соловых, В.С. Лукьянцев, С.А. Душкин, Г.В. Сударенков, аспиранты

Orenburg State Agrarian University, Orenburg, Russia

Оренбургский государственный аграрный университет, г. Оренбург, Россия

E-mail: ansolovykh@yandex.ru, lukans@mail.ru, s.duschkin@mail.ru, german-sudar@yandex.ru

Received December 16, 2011

\begin{abstract}
АННОТАЦИЯ
Установлено, что в условиях Оренбургского Предуралья перед посевом яровой пшениць наилучшие показатели по увлажнению и структурно-агрегатному составу чернозема обыкновенного в среднем наблюдались в балке, на северном склоне и плакоре, а наихудшие - на южном склоне, однако тенденция в пространственном изменении благоприятных показателей пористости почвы и во времени была прямо противоположной.
\end{abstract}

\begin{abstract}
It is established that in the conditions of Orenburg Preduralje before planting spring wheat crops the best indicators on humidifying and structurally-modular structure of chernozem ordinary were on the average observed in a beam, on northern slope and watershed, and the worst - on a southern slope, however the tendency in spatial change of favorable indicators of porosity of soil and in time was opposite.
\end{abstract}

\section{КЛЮЧЕВЫЕ СЛОВА}

Мезоформы рельефа; Чернозем обыкновенный; Влажность почвы; Агрофизические свойства почвы; Яровая пшеница.

\section{KEY WORDS}

Relief mesoforms; Chernozem ordinary; Humidity of soil; Agrophysical properties of soil; Spring wheat.

Разнообразие, неоднородность почвенного покрова, геоморфологических форм и элементов, других экологических факторов общеизвестно. Редко представляется возможность выделить сельскохозяйственный производственный участок, сравнительно большой площади и абсолютно идентичный на всей поверхности по условиям почв, рельефа, гидрологии и микроклимата. Наибольшей неоднородностью характеризуется почвенный покров (Годельман, 1981).

С учетом микроклимата каждого отдельного поля (земельного участка), обу- словленного рельефом местности, неодинаковым гранулометрическим составом, а также его изменения по территории, необходимо определять структуру посевных площадей и севооборотов, дифференцировать сортовой состав сельскохозяйственных культур, сроки и способы механической обработки почвы, сроки и нормы посева (посадки) сельскохозяйственных культур, сроки, дозы и способы внесения удобрений, а также способы уборки урожая.

Влажность почвы является одним из факторов, определяющих условия произра- 
стания сельскохозяйственных культур. Для большинства районов нашей страны неустойчивость урожаев от года к году, а местами и низкие их средние уровни, обуславливаются несоответствием имеющихся в почве запасов влаги и потребности в ней растений. Связь урожаев с увлажнением почвы наблюдается повсеместно.

Материалы и методы исследований. Исследования проводились в 2006-2010 гг. в лабораториях химической защиты растений Оренбургского ГАУ. Закладка полевых и производственных опытов проводилась в условиях КФХ «Соловых А.Д.» Переволоцкого района Оренбургской области.

Рельеф хозяйства в целом холмистоувалистый. Почвенный покров представлен в основном обыкновенными черноземами: черноземы обыкновенные тяжело- и среднесуглинистые; - черноземы обыкновенные карбонатные среднесмытые тяжело- и среднесуглинистые.

Гидротермические коэффициенты периодов вегетации: в 2006 г. 0,61; в 2007 г. 0,72; в 2008 г. - 0,67, характеризуются как слабо засушливые, 2005 г. и 2009 г. отмечались сильно засушливыми с показателями ГТК - 0,46 и 0,44 соответственно, в 2010 г. отмечалась очень сильная засуха, ГТК $-0,16$. В среднем за шесть лет ГТК $-0,51$.

Для проведения полевых опытов использовался сорт яровой мягкой пшеницы Юго-Восточная 2, с нормой высева 4,5 млн. на 1 га всхожих семян.

Производственный опыт закладывался в трехкратной повторности по следующим мезоформам рельефа: плакор водораздельный протяженностью 200 м, шириной 330 м; склон южный протяженностью 120 м, крутизной $3-5^{\circ}$; балка протяженностью $50 \mathrm{~m}$; склон северный протяженностью 150 м, крутизной $4-7^{\circ}$. В севообороте предшествующей культурой была яровая пшеница. Агротехника опыта была типичной для центральной климатической зоны Оренбургской области. Осенью проводили дискование почвы БТп 3-3 на глубину 20 см, весной закрытие влаги почвы - БЗСС - 1 в два следа, предпосевная культивация осуществлялась перед посевом - КПЭ-3,8 на глубину 8-10 см, посев - сеялкой СЗУ-3,6 на глубину 6-7 см.. Размер опытных делянок: плакор 7,2 × 200 м $=1440$ м2; южный склон $-7,2 \times 120$ м $=864$ м2; балка - 7,2 × 50 м $=360$ м2; северный склон $7,2 \times 150 \mathrm{M}=1080 \mathrm{M} 2$.

Проводились учеты и наблюдения за почвой:

- водно-физические свойства почвы по общепринятым методикам (Доспехов, Васильев, Туликов, 1987; Ряховский, Батурин, Березнёв, 2004).

- оценка метеорологических условий в годы исследований проводилась с использованием данных Оренбургской ГМС;

- влажность почвы - термовесовым методом (Н.А.Качинский, 1970). Почвенные пробы отбирали буром на глубину до одного метра послойно через 10 см на всех вариантах, в трехкратном повторении на делянке опыта в два срока: в период всходов и в день уборки урожая;

- плотность почвы методом цилиндров по С.И.Долгову - по слоям 0-10 см, 10-20 и 20-30 см в трехкратном повторении в начале и конце вегетации;

- агрегатный состав методом Н.И. Савинова (сухое просеивание).

Результаты исследований. В условиях Оренбургского Предуралья лимитирующим фактором является количество осадков, выпавших в весенне-летний период, поэтому нами была определена влажность почвы посева яровой пшеницы по горизонтам в метровом слое на различных элементах рельефа (табл. 1).

В 2007 г. количество осадков за период вегетации выпало в пределах нормы (за майавгуст 138 мм, норма - 133 мм). Влажность почвы перед посевом по мезоформам рельефа была большей в балке, запас общей влаги составил $25,7 \%$ и на северном склоне $24,3 \%$. На плакоре водораздельном и южном склоне запас общей влаги был в пределах 23,0-23,6\%. К уборке запасы влаги распределялись аналогичным образом. В 2008 г. создались практически такие же условия, как и в 2007 г.

В 2009 г. из 129 мм осадков, выпавших за май-август, 34 мм выпали только в июнеиюле, что неблагоприятно сказалось на развитии и состоянии растений.

На плакоре водораздельном запас общей влаги почвы перед посевом в слое 0-30 см составил 90,7 мм; на южном склоне 84,4 ; в балке - 93,5; на северном склоне 94,0 мм. 
Таблица 1 - Влияние мезоформ рельефа на влажность почвы в посевах яровой пшеницы в верхнем метровом слое почвы (средние данные за 2007-2009 гг.)

\begin{tabular}{|c|c|c|c|c|c|}
\hline \multirow{2}{*}{ Вариант опыта } & \multirow{2}{*}{ Горизонт, см } & \multicolumn{2}{|c|}{$\begin{array}{c}\text { Влажность почвы } \\
\text { перед посевом }\end{array}$} & \multicolumn{2}{|c|}{$\begin{array}{c}\text { Влажность почвы } \\
\text { перед уборкой }\end{array}$} \\
\hline & & $\%$ & $\begin{array}{c}\text { запас общей } \\
\text { влаги, мм }\end{array}$ & $\%$ & $\begin{array}{c}\text { запас общей } \\
\text { влаги, мм }\end{array}$ \\
\hline \multirow{3}{*}{ Плакор водораздельный } & $0-30$ & 23,9 & 90,7 & 16,3 & 62,3 \\
\hline & $0-50$ & 23,0 & 152,9 & 15,9 & 102,6 \\
\hline & $0-100$ & 21,4 & 272,4 & 14,7 & 186,8 \\
\hline \multirow{3}{*}{ Южный склон } & $0-30$ & 22,9 & 84,4 & 16,2 & 57,8 \\
\hline & $0-50$ & 22,0 & 143,0 & 15,8 & 104,3 \\
\hline & $0-100$ & 20,6 & 266,5 & 15,2 & 167,2 \\
\hline \multirow{3}{*}{ Балка } & $0-30$ & 25,1 & 93,5 & 16,6 & 58,0 \\
\hline & $0-50$ & 24,2 & 159,5 & 16,0 & 100,7 \\
\hline & $0-100$ & 22,6 & 283,0 & 15,2 & 195,0 \\
\hline \multirow{3}{*}{ Северный склон } & $0-30$ & 24,8 & 94,0 & 16,2 & 60,3 \\
\hline & $0-50$ & 24,1 & 158,7 & 16,0 & 108,2 \\
\hline & $0-100$ & 22,7 & 287,7 & 15,5 & 194,3 \\
\hline
\end{tabular}

Запас общей влаги в слое $0-30$ см перед уборкой составил: на плакоре 62,3 мм; южном склоне - 57,8; в балке - 58,0; на северном склоне - 60,3 мм.

Таким образом, запасы влаги в пахотном горизонте перед посевом были наибольшими в балке и на северном склоне, минимальными - на южном склоне; перед уборкой культуры они достигали максимума на плакоре, минимума - в балке и на южном склоне, что оказало неоднозначное влияние на развитие и урожайность пшеницы, ее пораженность корневыми гнилями.

В табл. 2 представлены данные по структурно-агрегатному составу почвы на различных элементах рельефа. Пользуясь качественными оценками структуры на основании количества агрегатов агрономически ценного диапазона - 10,00-0,25 мм, можно сделать вывод, что на плакорном участке хорошее агрегатное состояние (коэффициент структурности равен 1,45$)$. На южном и северном склонах коэффициент структурности составил - соответственно 1,20 и 1,25 , также характеризуется хорошим агрегатным состоянием. В балке более $60 \%$ агрегатов (отличное агрегатное состояние) входят в агрономически ценный диапазон, коэффициент структурности равен 1,78.

Из этого следует, мезоформы рельефа оказывают существенное влияние на структурно-агрегатный состав почвы с его высокими показателями в балке, затем на плакоpe, меньшими - на южном склоне.

Исследованиями сибирских ученых выяснено, что оптимальная плотность почвы при почвозащитных обработках на выщелоченном черноземе Западной Сибири может рассматриваться как один из факторов, существенно улучшающих фитосанитарное состояние хлебных злаков по почвенным вред-ным организмам, особенно распространенным фузариозно-гельминтоспо-риозным корневым гнилям.

При оптимальной плотности почвы создаются самые благоприятные для растений водно-воздушный, тепловой и пищевой режимы, что оказывает решающее влияние на долговременную физиологическую устойчивость и выносливость растений к биотическим (вредные организмы) и абиотическим (засуха) факторам (Чулкина, Торопова, Чулкин, Стецов, 2000). Нами была принята попытка выяснить, как мезоформы рельефа влияют на такие агрофизические свойства почвы, как плотность и пористость, которые в свою очередь влияют на рост и развитие растений и жизнедеятельность возбудителей болезней, в частности, корневых гнилей (Bipolaris sorokiniana и грибы рода Fusarium).

Данные по плотности и пористости пахотного слоя почвы на различных элементах рельефа отражены в табл. 3.

Мезоформы рельефа оказывали незначительное влияние на плотность почвы. В слое 0-30 см почвы на плакоре и южном склоне были более рыхлыми перед посевом, а сравнительно плотными перед уборкой культуры. В балке и на северном склоне наблюдалась обратная тенденция. В фазы всходов и перед уборкой культуры почвы были наиболее пористыми на южном склоне, затем условия аэрации почвы заметно ухудшались к плакору, затем к северному склону и балке. 
Таблица 2 - Влияние мезоформ рельефа на структурно-агрегатный состав почвы (2009 г.)

\begin{tabular}{|c|c|c|c|c|}
\hline $\begin{array}{c}\text { Вариант } \\
\text { опыта }\end{array}$ & $\begin{array}{c}\text { Размер } \\
\text { фракции, } \\
\text { мм }\end{array}$ & $\begin{array}{c}\text { Масса } \\
\text { фракции, } \\
\text { г }\end{array}$ & $\%$ & $\begin{array}{l}\text { Коэффициент } \\
\text { структурности }\end{array}$ \\
\hline \multirow{8}{*}{$\begin{array}{c}\text { Плакор } \\
\text { водораздельный }\end{array}$} & более 10 & 49,3 & 24,7 & \multirow{8}{*}{1,45} \\
\hline & $10-7$ & 12,9 & 6,4 & \\
\hline & $7-5$ & 13,6 & 6,8 & \\
\hline & $5-3$ & 16,8 & 8,4 & \\
\hline & $3-1$ & 31,0 & 15,5 & \\
\hline & $1-0,5$ & 15,0 & 7,5 & \\
\hline & $0,5-0,25$ & 29,3 & 14,7 & \\
\hline & менеe 0,25 & 32,1 & 16,1 & \\
\hline \multirow{8}{*}{ Южный склон } & более 10 & 69,2 & 34,6 & \multirow{8}{*}{1,20} \\
\hline & $10-7$ & 10,0 & 5,0 & \\
\hline & $7-5$ & 12,9 & 6,5 & \\
\hline & $5-3$ & 15,0 & 7,5 & \\
\hline & $3-1$ & 28,5 & 17,6 & \\
\hline & $1-0,5$ & 15,1 & 7,6 & \\
\hline & $0,5-0,25$ & 24,3 & 8,4 & \\
\hline & менее 0,25 & 18,3 & 9,2 & \\
\hline \multirow{8}{*}{ Балка } & более 10 & 29,1 & 14,6 & \multirow{8}{*}{1,78} \\
\hline & $10-7$ & 18,8 & 9,4 & \\
\hline & $7-5$ & 15,1 & 7,6 & \\
\hline & $5-3$ & 11,4 & 5,7 & \\
\hline & $3-1$ & 21,7 & 10,8 & \\
\hline & $1-0,5$ & 32,9 & 16,5 & \\
\hline & $0,5-0,25$ & 28,1 & 14,1 & \\
\hline & менее 0,25 & 42,8 & 21,4 & \\
\hline \multirow{8}{*}{ Северный склон } & более 10 & 60,8 & 30,4 & \multirow{8}{*}{1,25} \\
\hline & $10-7$ & 18,7 & 9,4 & \\
\hline & $7-5$ & 13,0 & 6,5 & \\
\hline & $5-3$ & 13,8 & 6,9 & \\
\hline & $3-1$ & 26,8 & 13,4 & \\
\hline & $1-0,5$ & 10,7 & 5,4 & \\
\hline & $0,5-0,25$ & 28,0 & 14,0 & \\
\hline & менее 0,25 & 28,1 & 14,1 & \\
\hline
\end{tabular}

Таблица 3 - Влияние мезоформ рельефа на плотность и пористость почвы (в среднем за 2007-2009 гг.)

\begin{tabular}{|c|c|c|c|c|c|c|c|}
\hline \multirow{3}{*}{$\begin{array}{c}\text { Вариант } \\
\text { опыта }\end{array}$} & \multirow{3}{*}{$\begin{array}{c}\text { Слой } \\
\text { почвы, } \\
\text { см }\end{array}$} & \multicolumn{2}{|c|}{ 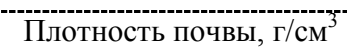 } & \multicolumn{4}{|c|}{ Пористость, \% } \\
\hline & & \multirow{2}{*}{$\begin{array}{c}\text { перед } \\
\text { посевом }\end{array}$} & \multirow{2}{*}{$\begin{array}{c}\text { перед } \\
\text { уборкой }\end{array}$} & \multicolumn{2}{|c|}{$\begin{array}{l}\text { весеннее } \\
\text { отрастание }\end{array}$} & \multicolumn{2}{|c|}{$\begin{array}{c}\text { перед } \\
\text { уборкой }\end{array}$} \\
\hline & & & & общая & аэрации & общая & аэрации \\
\hline \multirow{4}{*}{$\begin{array}{c}\text { Плакор водо- } \\
\text { раздельный }\end{array}$} & $0-10$ & 1,10 & 1,31 & \multirow{4}{*}{54,0} & \multirow{4}{*}{27,7} & \multirow{4}{*}{51,6} & \multirow{4}{*}{36,5} \\
\hline & $10-20$ & 1,19 & 1,36 & & & & \\
\hline & $20-30$ & 1,26 & 1,38 & & & & \\
\hline & $0-30$ & 1,19 & 1,33 & & & & \\
\hline \multirow{4}{*}{ Южный склон } & $0-10$ & 1,10 & 1,26 & \multirow{4}{*}{55,7} & \multirow{4}{*}{29,2} & \multirow{4}{*}{53,6} & \multirow{4}{*}{37,5} \\
\hline & $10-20$ & 1,21 & 1,38 & & & & \\
\hline & $20-30$ & 1,27 & 1,37 & & & & \\
\hline & $0-30$ & 1,19 & 1,33 & & & & \\
\hline \multirow{4}{*}{ Балка } & $0-10$ & 1,15 & 1,27 & \multirow{4}{*}{53,0} & \multirow{4}{*}{25,2} & \multirow{4}{*}{50,4} & \multirow{4}{*}{34,7} \\
\hline & $10-20$ & 1,23 & 1,37 & & & & \\
\hline & $20-30$ & 1,28 & 1,46 & & & & \\
\hline & $0-30$ & 1,22 & 1,36 & & & & \\
\hline \multirow{4}{*}{$\begin{array}{l}\text { Северный } \\
\text { склон }\end{array}$} & $0-10$ & 1,12 & 1,29 & \multirow{4}{*}{54,0} & \multirow{4}{*}{25,9} & \multirow{4}{*}{50,9} & \multirow{4}{*}{36,0} \\
\hline & $10-20$ & 1,23 & 1,44 & & & & \\
\hline & $20-30$ & 1,29 & 1,43 & & & & \\
\hline & $0-30$ & 1,21 & 1,36 & & & & \\
\hline
\end{tabular}


По мнению А.А. Бочкова, И.Ф. Медведева, М.Н.Любимовой, Л.Б. Сайфулиной (2010), изменения агрофизических характеристик связаны с особенностью экологических условий склонов, плотность сложения почвы под травами в нижней части склона по сравнению с вершиной снижается на $0,18 \mathrm{r} / \mathrm{cm}^{3}$, в зернопаровом севообороте - на $0,10 \Gamma / \mathrm{cm}^{3}$.

Таким образом, перед посевом и в фазу всходов яровой пшеницы в слое почвы 0-30 см наилучшие показатели по увлажнению и структурно-агрегатному составу в среднем наблюдались в балке, затем на северном склоне и плакоре, а наихудшие на южном склоне, однако тенденция в пространственном изменении благоприятных показателей пористости почвы была прямо противоположной. По мере вегетации культуры к фазе полной спелости соотношение показателей пористости почвы в корнеобитаемом слое по мезоформам рельефа практически не изменилось, запасы влаги в почве также, как и перед посевом, оставались наименьшими на южном склоне. Наиболее увлажненными почвы были на плакоре, запасы влаги в них заметно снижались на северном склоне и в балке. От посева к уборке культуры запасы влаги в слое почвы 0-30 см уменьшились в балке на 35,5 мм; на северном склоне - на 33,7 ; плакоре - на 28,4 и на южном склоне - на 26,6 мм.

\section{БИБЛИОГРАФИЯ}

Годельман, Я.М. Неоднородность почвенного покрова и использование земель. - М.: Наука, 1981. - 200 с.

Бочков, А.А. Оптимизация физического состояния склоновых черноземных почв /А.А.Бочков, И.Ф.Медведев, М.Н.Любимова и др. //Молодые ученые - агропромышленному комплексу Поволжья. - Саратов: ГНУ НИИ сельского хозяйства Юговостока, 2010. - С. 234-238.
Ряховский, А.В. Агрономическая химия (в приложении к условиям степных районов России) /А.В.Ряховский, И.А.Батурин, А.П.Березнев. - Оренбург, 2004. -283 с.

Чулкина, В.А. Агротехнический метод защиты растений /В.А.Чулкина, Е.Ю.Торопова, Ю.И.Чулкин и др.: Учебное пособие. - М.: ИВЦ «МАРКЕТИНГ», Новосибирск: ООО «Издательство ЮКЭА», 2000. - 336 с. 